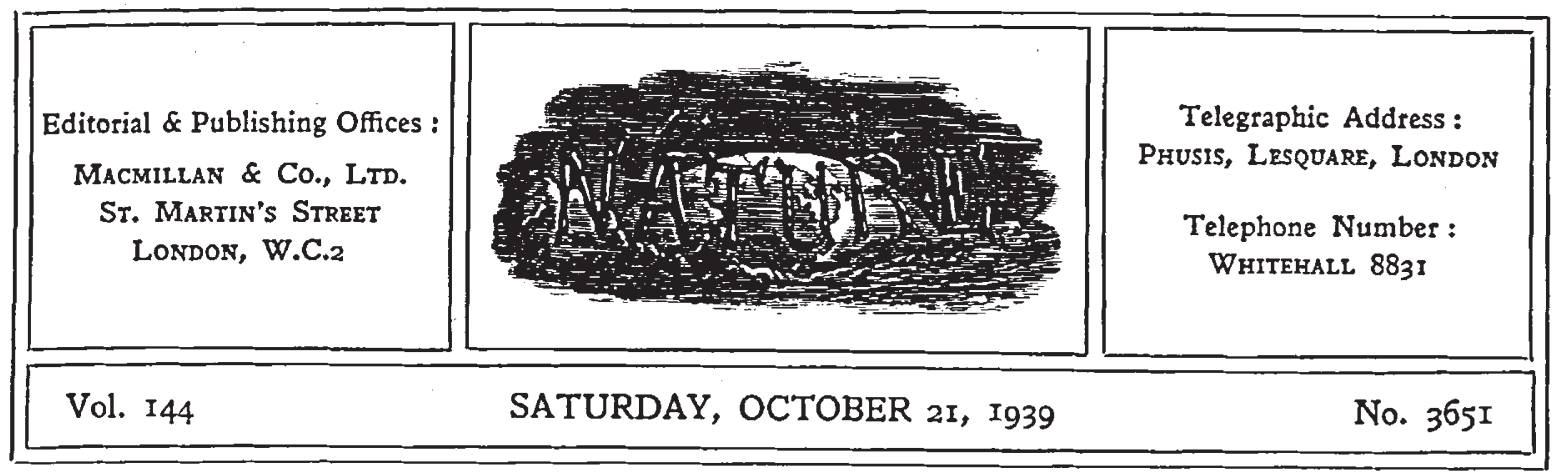

\title{
PLANNED INTERNATIONAL ECONOMICS
}

$\mathrm{T}$ HE high position of the annual reports of the Director of the International Labour Office among current reviews of the industrial and economic condition of the world has been earned only in part by the large resources of knowledge upon which they can draw. It is equally due to their wide outlook, measured but unequivocal judgment and their lucid estimate of tendencies and conditions, free from excessive detail of the work of the organization. These are largely due to personal qualities, and it is indeed a high tribute to Mr. J. E. Winant that his first annual report so admirably maintains the high standard set by his predecessors*. The fact that this report was published before the outbreak of war in no way lessens its present value.

Under the title "The World of Industry and Labour 1939", Mr. Winant reviews in succession the economic setting, the conditions of work and the standards of life. He emphasizes the way in which research and discussions on business cycle policy have led to general agreement that, whatever the initial cause of a business decline, active steps can be taken to prevent the secondary effects which used inevitably to follow it, and that this can be achieved by maintaining consumers' demand and by well-prepared public investment to replace rapidly any decline in private investment. This new attitude is conspicuous in the United States, and economic policy in Great Britain has shown similar features. While, however, the recession of 1937-38 presented mainly a problem of getting unemployed people back to work, the general concentration on problems of national defence has given a new turn to the economic

*The World of Industry and Labour, 1939. International Labour Ofice. Report of the Director. (Geneva: International Labour Oflice. 2e.). situation. In this situation the urgency of meeting essential needs of national defence tends to cut into the standards of living, which it is the work of the International Labour Organisation to endeavour to raise.

To minimize such an effect it is first desirable to increase armament production so far as possible by utilizing unemployed resources, so as not to disturb ordinary peace-time activities more than necessary. Secondly, when it is necessary to restrict other types of activity or production, care should be taken to confine such restriction to the minimum and to those fields which least jeopardize present and future standards of living. While both public spending designed as a recovery measure and expenditure on armaments cause an initial increase in activity, the latter must be accompanied by measures to prevent expansion of consumption and a rise in standards of living.

These threats to established standards and the growing pressure on resources accentuate the importance of international economic co-operation. The rising standard of living in modern times has bcen made possible by the expansion of markets and the world-wide exchange of raw materials, finished products and capital investment. The hope of further progress rests on the continuance of this process.

The main problem is always to organize world economy in a way that will utilize fully the capacities of mankind in the production of the goods and services needed to raise the standard of life. Mr. Winant's survey of conditions of work indicates how true this is of internal economy also. Political conditions have been the main factor determining the check on the movement for shorter hours and the hesitation in giving effect to 
the application of the principle of the forty-hour week adopted by the Conference in 1935. This remains, however, a permanent problem of social and economic policy, and the realization of shorter rrorking hours is one of the great additional benefits that will be assured when nations will agree to a just and lasting peace.

There are, however, directions in which progress has been made. The development and extension of social insurance and the widespread attention being given to problems of nutrition, whether from the scientific side or in Government efforts to raise the level of nutrition by means of education and publicity, are noteworthy examples. Housing also is a matter in which the State is taking a more active part.

What is of special interest in Mr. Winant's survey is the way in which he indicates the extent to which solutions of these problems were being attempted in many countries, and frequently by very similar methods, however different the objectives or main character of policy. This is scarcely less striking than the equally emphatic conclusion that success in this matter of improving standards of health and labour and living con. ditions can only be imperfectly achieved except through co-operation between the nations.

This report is, however, of further interest for the admirable review of the twenty years' work which has now been completed by the International Labour Office. This record of development as well as of achievement is a welcome reminder of the value of international co-operation. The continuous constructive effort by which the International Labour Conference has developed its technique is at least as impressive as the record of its achievement in establishing an international labour code and in assisting the organization and co-ordination of social policy on which the im. provement in living and working conditions depends. The work of the Conference on Migration for Settlement and of the International Public Works Committee are striking illustrations of the latter tendency in the last two years.

Besides this, the International Labour Office has functioned as an international clearing-house of information on labour and social questions. All these activities are based on its research work, and this possesses two special advantages. In its research work the International Labour Office must of necessity use the method of international comparison. The comparative method is to the student of social science what the laboratory is to the physicist. The Office cannot make experiments, but it is able to study the same phenomena in many different countries and thus eliminate what is accidental in the experience of any particular country and emphasize those things which are fundamental to all. Further, the International Labour Office is well placed for bridging the gulf between theory and action by bringing the conclusions reached directly before those capable of acting upon them.

Such rescarch work, coupled with the broad view and tripartite character of the International Labour Office which naturally follow from its constitution, have already assisted it, in such fields as economic depression and unemployment, or in that of industrial diseases, like silicosis, or the standardization of labour statistics and improvement of their comparability, to guide world opinion towards more effective methods.

The extent to which the International Labour Office has succeeded in the last twenty years in furthering steady social progress is at least reason for not losing confidence or hope. The full contribution of the Office to effective international collaboration is not to be measured only by such activities. In approaching labour and social problems, we are forced to face the economic consequence of war and peace, whether in relation to trade conflict or war economy. When the present war comes to an end, the countries of the world will have to face the tremendous problems of readjustment to a peace-time economy. Economic re:employment problems will demand urgent solution. Some means of absorbing workers thrown out of employment by the slowing down of armament production will have to be devised.

In facing such difficulties the International Labour Office already possesses resources of immense value, but if it is to render the greatest possible service its energies must be directed now to the problems that lie ahead. The research work required must be commenced in this period of tension and uncertainties if we are to ensure that the mistakes of the past are not to be repeated. It is on this fact as well as on the proved value of the Organisation that Mr. Winant bases his appeal for financial support and for the resources which will enable it to function effectively. The extent to which the services of scientific workers are being enlisted at the present time should not lead them to overlook their responsibilities for participation in the constructive work of thinking out and planning the implications of a real peace. 